\title{
Author Spotlight: Emilie Regner
}

\section{Emilie Regner $^{1}$}

Published online: 14 July 2020

(c) Springer Science+Business Media, LLC, part of Springer Nature 2020

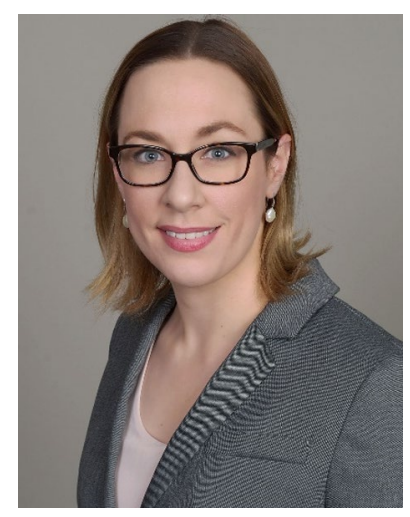

Dr. Emilie Regner is currently an advanced IBD fellow at University of California, San Francisco, under the mentorship of Dr. Uma Mahadevan. She completed her internal medicine residency and gastroenterology fellowship at University of Colorado. Following her graduation, she will be joining the IBD faculty at Oregon Health and Sciences University. Her clinical and research interests include inflammatory bowel disease, extra-intestinal disease manifestations of IBD, liver disease in IBD, and pregnancy and fertility in women with IBD.

Publisher's Note Springer Nature remains neutral with regard to jurisdictional claims in published maps and institutional affiliations.
Emilie Regner

Emilie.Regner@ucsf.edu

1 University of California, San Francisco, San Francisco, CA, USA 